\title{
The effects of the probiotic Subtilis on the peripheral blood system of Clarias gariepinus
}

\author{
T. M. Shlenkina ${ }^{1, *}, E . M$. Romanova $^{1 *}, V . N$. Lyubomirova $^{1}, V . V$. Romanov $^{2}$, and $L . A$. Shadieva $^{1}$ \\ ${ }^{1}$ Department of Biology and Ecology, Ulyanovsk State Agrarian University named after P.A. Stolypin, 432017 Ulyanovsk, Russia \\ ${ }^{2}$ Department of Informatics, Ulyanovsk State Agrarian University named after P.A. Stolypin, 432017 Ulyanovsk, Russia
}

\begin{abstract}
The article discusses the prospects for using probiotics in aquaculture. The effect of probiotics on the physiological processes in the body of African catfish grown under artificial breeding is discussed. The effectiveness of using probiotics to increase productivity, improve the gastrointestinal tract of fish, increase non-specific resistance and stress resistance is analyzed. The results of our own research on the use of the probiotic Subtilis, which is currently used in many industries, including fish farming, are presented. The aim of the work was to study the effect of the probiotic subtilis on the erythron system and on the structure of the leukocyte formula of African catfish. Against the background of the probiotic subtilis, the total number of red blood cells in the bloodstream was increasing, and the proportion of immature forms was progressively decreasing. The seasonal dynamics and sexual characteristics of the catfish peripheral blood system were studied with the use of a probiotic. In general, the stimulating effect of the probiotic subtilis on erythropoiesis and the white blood system was found. Analysis of the leukogram of African catfish indicated the activation of the cellular component of the immune system when using a probiotic in feeding. Our results allow us to recommend the use of the probiotic subtilis for the cultivation of African catfish in industrial aquaculture. This work was supported by the Russian Foundation for Basic Research with the grant 18-016-00127.
\end{abstract}

\section{Introduction}

Currently, aquaculture is developing steadily throughout the world. The purpose of its development is to provide the population with a variety of fish products that are available to people with different income levels, as well as meeting the needs of adjacent industries for technical products.

Unlike natural conditions, under cultivation conditions in recirculation aquatic systems (RAS), fish is deprived of natural food, it lives in an aquatic environment that has lost its self-cleaning ability.

Under the influence of microflora of water and feed, changes occur in the microbiocenosis of the intestines of fish [1]. As a rule, they are negative. Violations in the composition of the intestinal microbiota lead to a weakening of growth, a high susceptibility of fish to diseases. In addition, fish are subject to stresses of various origins, which are inevitable during intensive cultivation and further aggravate the situation.

In the last decade, interest in probiotics has increased [2-4]. The widespread demand for probiotics in all sectors of agricultural production stimulated the emergence of many new probiotic preparations which are in demand in various industries.

By optimizing the microbiocenosis of the digestive tract, the microflora of probiotics increases the absorption of nutrients, thereby reducing feed costs. At the same time, not only feed is used more efficiently, but also the economic indicators of production increase significantly.

In the technological process of growing fish, there is a crucial critical moment when the fish larvae, having lost the yolk sac, begin to actively eat and constantly swallow water. Therefore, it is very important precisely during this period to colonize the fish intestine with microbiota, which has a healing effect on the intestinal microbiocenosis and enhances natural immunity. The use of probiotic allows one to create conditions for the growth and development of fish. In the contemporary aquaculture in many countries, African catfish (Clarias gariepinus) is becoming increasingly popular as an object of industrial fish breeding. And this is not surprising, since this species easily adapts to the environment, and, in addition, it reproduces quite easily and exhibits increased resistance to diseases [5].

At fish farms in the Russian Federation and European countries in recirculating aquatic systems (RAS), the most popular of all catfish species is the African catfish Clarias gariepinus, and not two closely related species, Clarias lazera and Clarias batrachus [6], which are widely used for growing mainly in tropical countries. nfectious diseases of fish are considered the most dangerous in aquaculture, they are accompanied by large losses of fish products. An important role in increasing

\footnotetext{
Corresponding author: t-shlenkina@yandex.ru
} 
the productivity of industrial and fish farming is the prevention and treatment of diseases. The main pathogens that cause fish diseases are aeromonads, pseudomonads, vibrios, many types of enterobacteria and Escherichia coli.

The use of probiotics in fish farms is one of the most effective solutions for preventing fish diseases and preventing water pollution from fish metabolites [7-9].

Quite recently, it was believed that probiotics have a narrow "intestinal" orientation. However, in recent years it has been found that probiotics have inherent immunomodulating effects, they also act as metabolic regulators [10].

A typical representative of probiotics is the domestic drug Subtilis, whose effective agent is Bacillus subtilis and Bacillus licheniformis. The microorganisms of this probiotic actively secrete biologically active substances in the intestine and produce various digestive enzymes and enzymes [11].

The dose of probiotics is selected in each case, depending on the species and age of fish, season, temperature. The effect of using probiotics in fish farming is undeniable, but the actions that implement these effects is still under study [12].

In particular, the effect of probiotics on the blood system of fish has not been sufficiently studied. Therefore, in our work, we study the effect of the probiotic Subtilis on the hematopoietic system, examining the erythron system and the leukogram.

The main objective of the study is to establish the nature of the effect of the probiotic Subtilis on the red and white blood system of African catfish (Clarias gariepinus).

\section{Materials and methods}

The material for the study was African catfish, grown in the laboratory of Experimental Biology and Aquaculture of the Ulyanovsk State Agrarian University.

For this purpose, two groups, the experimental and control one were formed. The groups included both males and females of African catfish, 25 specimen in each. In all groups, the fish were fed with extruded food "Limkorm", where the protein content was 46-52\%. Feeding was carried out manually, so as to ensure the fastest possible eating, the frequency of feeding was 3-4 hours.

For preventive maintenance, increasing productivity, normalizing digestion and improving the physiological state, the probiotic Subtilis-C was introduced into the diet of the experimental group of males and females in the amount of 40 grams per $1 \mathrm{~kg}$ of feed. The probiotic was dissolved and the compound feed was irrigated with it until completely absorbed, right before feeding. Probiotics were not used in feeding control groups of males and females of African catfish.

African catfish were kept in tanks of $3.8 \mathrm{~m} 3$ in RAS. The water temperature was maintained at $26^{\circ} \mathrm{C}$, the oxygen content in the water was $4 \mathrm{mg} / \mathrm{l}$.

Peripheral blood was taken intravitally from the caudal vein. To calculate the total number of red blood cells, a Burquer count camera was used with a Goroaev grid engraved on it. Erythrocyte counts were performed in 80 small squares located diagonally. For cell counting, 2-3 drops of a blood solution were used.

Blood was collected using a blood-count pipet for erythrocytes and pre-mixed with a $0.65 \% \mathrm{NaCl}$ solution. We counted all the cells lying not only inside the square itself, but also on its boundary lines, if most of the cells were in the inner part of the square. The average number of erythroid cells was determined as follows: the number of all counted cells was divided by the number of squares in which red blood cells were counted (80) and a value corresponding to the average number of cells containing $1 / 4000 \mathrm{~mm}^{3}$ was obtained. Multiplying the result by 4000 and the degree of dilution, we obtained an average erythrocyte content in $1 \mathrm{~mm}^{3}$.

Red blood cells were divided into blastocytes, immature erythrocytes and mature erythrocytes. The proportion of each group of red blood cells was determined by the formula:

$\mathrm{M}=\mathrm{n} / \mathrm{m} \times 100 \%$, where

$\mathrm{M}$ - the proportion of red blood cells of the studied group; $\mathrm{n}$ - specific red blood cell count; $\mathrm{m}$ - total number of red blood cells studied (Zhiteneva et al., 2004)

Blood smears were made at the place of capture, then they were fixed with $96^{\circ}$ ethanol. After drying, the preparations were stained according to the Romanowsky-Giemsa method. When calculating the forms of red blood cells and the leukocyte formula, an optical binocular microscope with an immersion lens was used. Cedar oil was used as immersion. On blood smears, all uniform blood elements found in the field of vision were counted successively, and on special forms they were marked depending on their belonging to one or another group.

According to the generally accepted technique, the counting of various forms of cells was started from the middle of the smear, moving the visual fields using the zigzag method to the edge of the glass slide, since the formed blood elements are located in different parts of the preparation due to their different specific gravity.

Statistical data processing was carried out by the method of variation statistics using the Excel program, the results of the differences were evaluated by the Student criterion, the differences were considered reliable at $\mathrm{P} \geq 0.05$.

\section{Results and discussion}

During the evolutionary process, blood, being the basis of the internal environment of the body, acquired a complex of especially important functions that ensure homeostasis, regulation and optimization of the relationship of the organism with the external environment.

Hematological parameters are an indicator of the body's reactions to various stress effects. According to the reaction of the blood system in response to the effects of adverse factors, their influence on the physiological state of fish can be estimated. 
Blood is one of the most flexible systems of the organism in relation to environmental factors. This property is due to its composition and functions. The ratio of different forms of red blood cells in the peripheral blood of fish is a rather informative indicator that reflects various aspects of the vital activity of its body. These include: health status, species specifics, seasonal changes, way of life characteristics, nutrition, habitat, stages of the life cycle, etc.

Blood performs many functions. Of paramount importance is oxygen transport, no less important are the transfer of nutrients from the digestive system to other tissues, of metabolites from the place of formation to the sites of neutralization and excretion, the transfer of hormones from the endocrine glands to the tissues, and the transport of immunity factors.

These functions are mostly inherent in red blood cells. They transfer nutrients adsorbed on the surface and biologically active substances, exchange lipids with blood plasma, participate in the regulation of acid-base and ionic equilibrium, water-salt metabolism. Due to adsorption on the surface of cells of various substances, red blood cells indirectly participate in immune responses, as well as in the regulation of blood coagulation system [13].

But the main function of red blood cells can be considered respiratory function, i.e. the ability to bind and transport oxygen and carbon dioxide. This function is carried out by hemoglobin contained in red blood cells.

The red blood cells of fish in the bloodstream live quite a long time, about a year, which is apparently associated with the functional activity of hemoglobin molecules.

A characteristic feature of fish is the polymorphism of red cells, this is expressed in the fact that erythroid cells of varying degrees of maturity can simultaneously be present in the bloodstream. Red blood cells are divided into mature red blood cells and immature forms.

The number of red blood cells in the body of fish depends on many indicators. Their fluctuation can be affected by sexual activity, spawning, season of the year, time of day, nutrition, starvation and a number of other parameters.

The results of our studies showed that in winter the number of red blood cells in males in the control group was $1.38 * 10^{12} / 1$, in the spring $-1.49 * 10^{12} / 1$, which is $5.5 \%$ more. In the experimental group in winter, this indicator was equal to $1.51 * 10^{12} / \mathrm{l}$, which is $11.92 \%$ lower than in spring. The number of red blood cells in males of the control group in winter was $6.79 \%$ lower than in the experimental group, and in the spring period the difference was $4.27 \%$.

Blast cells are undifferentiated blood cells that are produced in the bone marrow. Subsequently, they are converted to red blood cells, white blood cells and platelets. They are the precursors of mature blood cells. In our experience, an insignificant amount of these cells was noted. They amounted to $0.1 \%$.

The erythrocyte count in fish in the experimental group in the winter period was higher by $9.4 \%$ compared with the control. There is a tendency of increase in mature forms of red blood cells in the experimental group due to a decrease in immature ones (Fig. 1).

Males of the control group in the winter had five times more mature red blood cells was than immature ones. The number of mature red blood cells was $84.0 \%$, and of immature ones - $15.9 \%$. In the experimental group, the number of mature forms of red blood cells was 8.8 times greater than immature ones.

We can see that the number of mature red blood cell forms in the experimental group was $5.7 \%$ higher than in the control group. The content of non-mature forms in the experimental group, on the contrary, was lower than in the control group by 1.5 times.

Thus, the number of immature forms of erythrocytes is apparently related to the seasonal activation of metabolism in the body of catfish. The presence of red blood cell precursors - blastocytes in the spring period of time was noted only in the control group (Fig. 2).

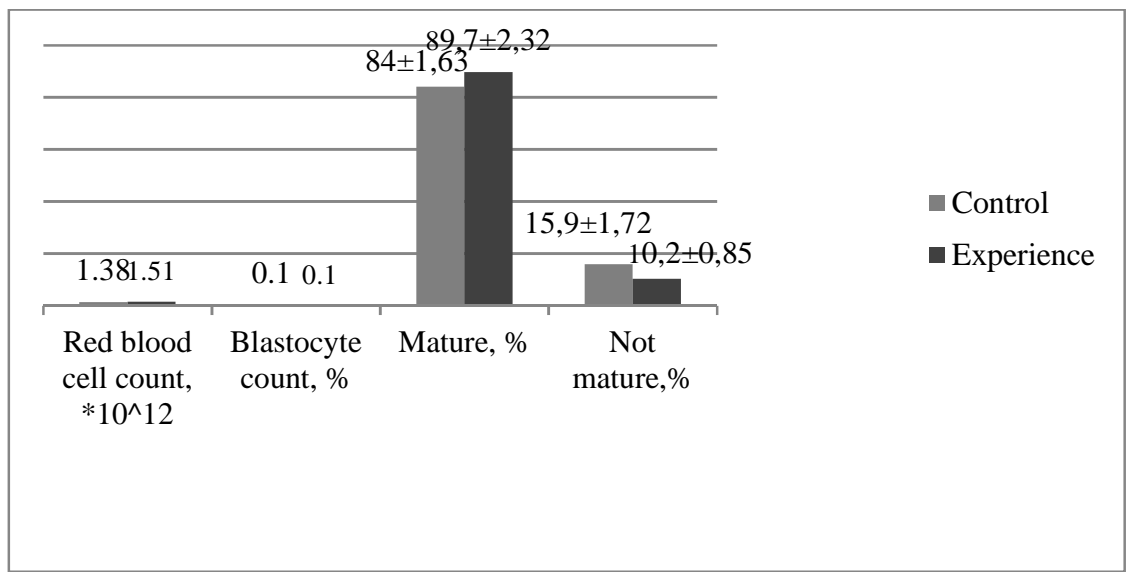

Fig. 1. The content of different groups of red blood cells in the blood of males of African catfish on the background of a probiotic in the winter period. 


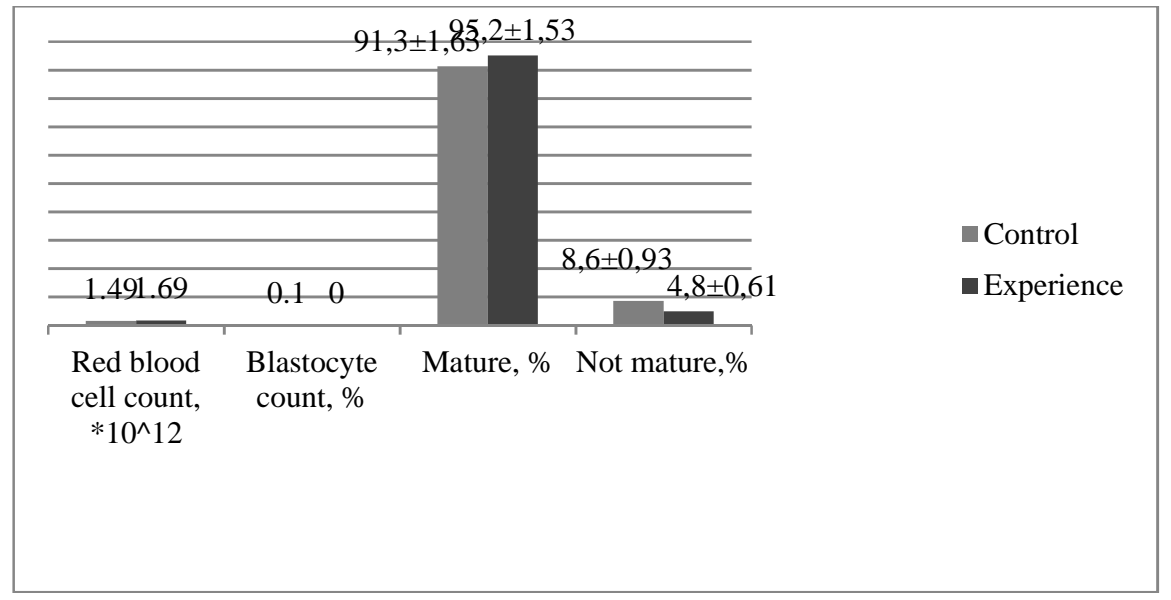

Fig. 2. The content of different groups of red blood cells in the blood of males of African catfish against the background of a probiotic in the spring period.

The total number of red blood cells in the spring in males of the experimental group was higher than in specimen of the control group by $13.4 \%$. The proportion of mature forms of red blood cells in the experimental group increased, due to this there was a decrease in immature forms. Thus the number of mature forms of red blood cells in the control group was $91.3 \pm 1.63 \%$, in the experimental group $-95.2 \pm 1.53 \%$.

There were no statistically significant differences in the content of immature forms in the blood of fish, but a pronounced tendency existed, since the proportion of immature forms of red blood cells in the experimental group was 1.79 times lower than in the control group.

The results of the study of the content of red blood cells in females with the use of the probiotic are shown in Figures 3, 4.

Based on the data obtained, it is possible to judge the change in the content of red blood cells in the blood of female African catfish.

The content of red blood cells in the blood of females was of the same orientation as that of males. So the number of red blood cells in the spring in the control group was $1.77 * 10^{12} / 1$, which is $6.5 \%$ more than in winter. In winter, the erythrocyte content in the experimental group was $6.7 \%$ higher than in the control, in the spring, these differences were $8.47 \%$.

The seasonal dynamics of the content of mature forms of red blood cells in the control group had the same orientation as the total number of red blood cells. In winter, the proportion of mature forms of red blood cells in the control group was 1.09 times less than in the experimental group. The number of immature red blood cells in the experimental group, compared with the control, was 2.03 times lower.

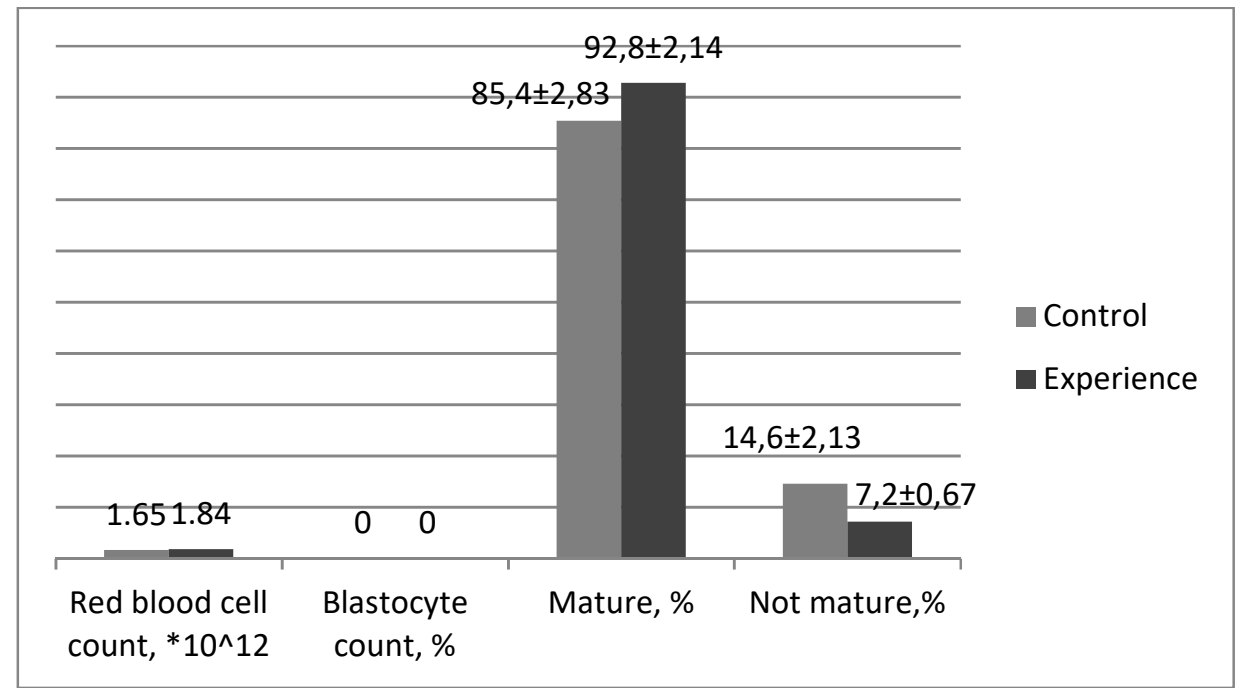

Fig. 3. The content of different groups of red blood cells in the blood of female African catfish on the background of the probiotic in winter period. 


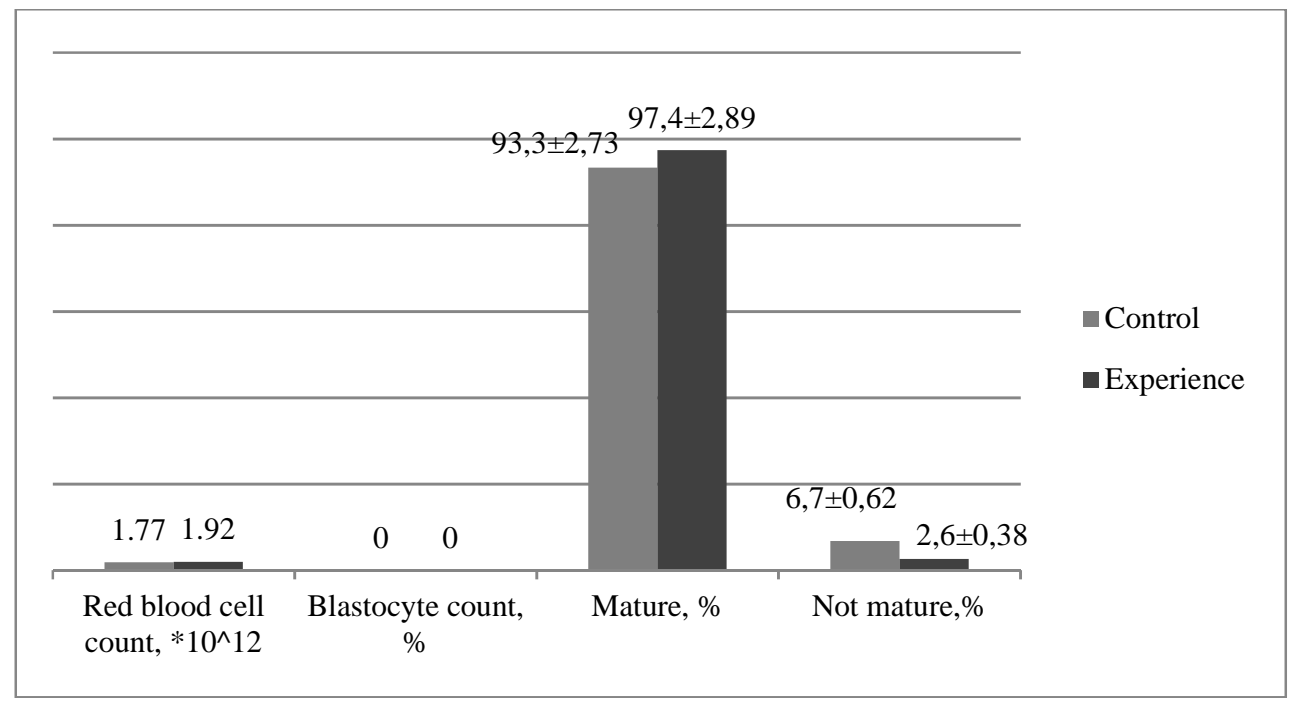

Fig. 4. The content of different groups of red blood cells in the blood of female African catfish on the background of the probiotic in the spring period.

Blood counts objectively reflect the intensity of metabolic processes occurring in the body of fish, and have high correlative relationships with age, season, nutrition and other factors affecting normal growth and development. A photograph of the red blood cells of an African catfish is shown in Fig. 5. Counting was performed under a small magnification of the microscope (eyepiece $\times 10$, lens $\times 8$ ).

In the case of lack of red blood cells in the bloodstream, they will not be able to effectively cope with the delivery of oxygen. Reduced red blood cell count causes a deficiency of hemoglobin and iron ions, which bind oxygen and supply it to tissues. Oxygen deficiency negatively affects the work of all organs and systems of the body. In this case, oxygen starvation of organs and tissues will occur.

Another important hematological indicator is a leukogram. It expresses the percentage of different types of white blood cells. Leukoformula is an indicator of not only the physiological state of fish, but also the state of cellular immunity. The composition of the leukoformula of African catfish was studied by us against the background of the probiotic Subtilis in mature males and females. The leukogram of males is shown in Figure 6 and leukogram of females - in Figure 7.

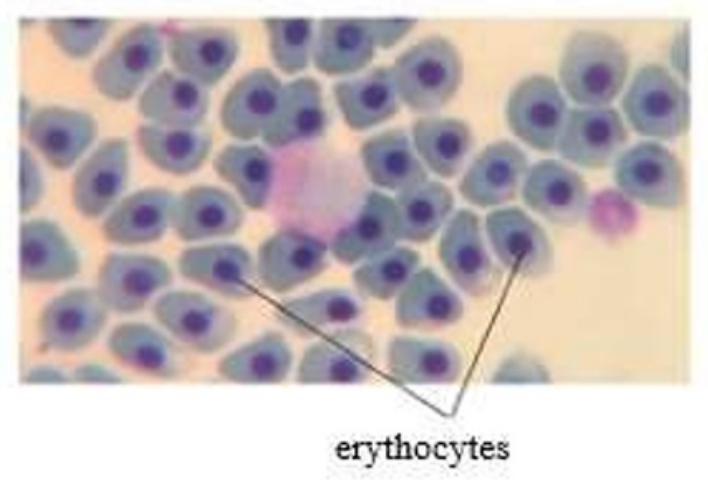

Fig. 5. Red blood cells of a mature African catfish

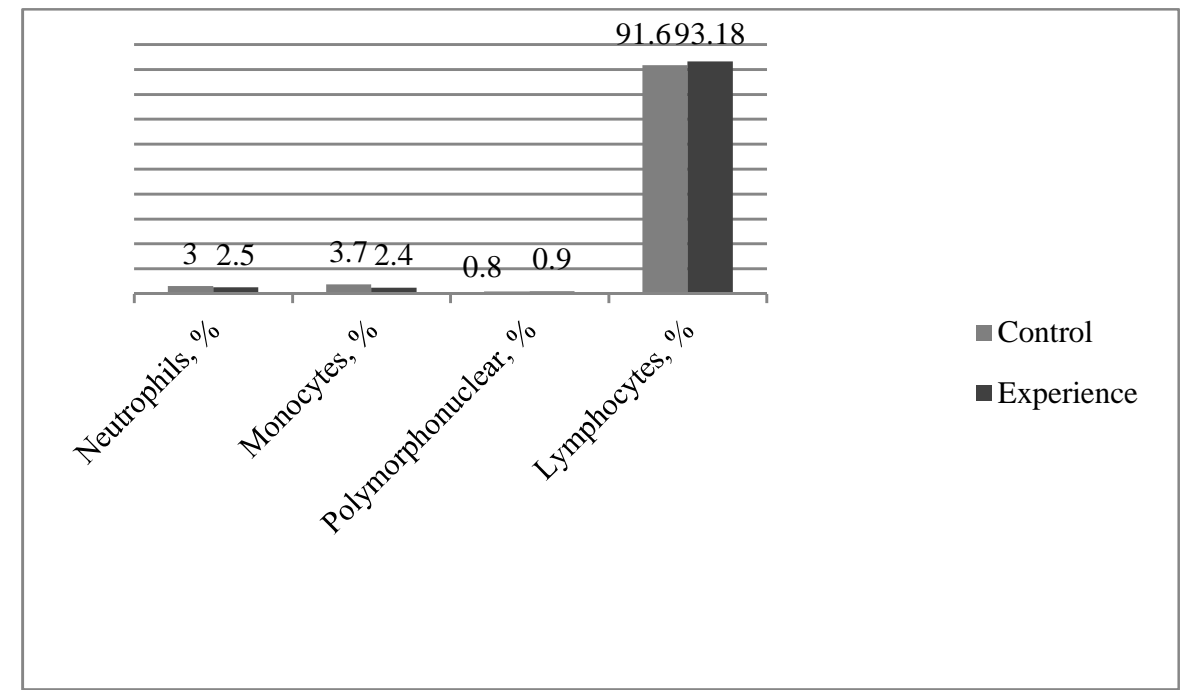

Fig. 6. Leukocyte formula of male African catfish catfish (\%) 
The white blood morphology of catfish was characterized by the predominance of lymphocytes. These cells are most represented in the leukogram and comprise from $89.52 \%$ to $93.18 \%$ in African catfish. Monocytes were found in blood smears among agranulocytes. They accounted for $2.4-3.8 \%$ of the total number of leukocytes. Monocytes had a blue-violet large nucleus of a rounded shape and a narrow rim of the cytoplasm, painted in a smoky color.

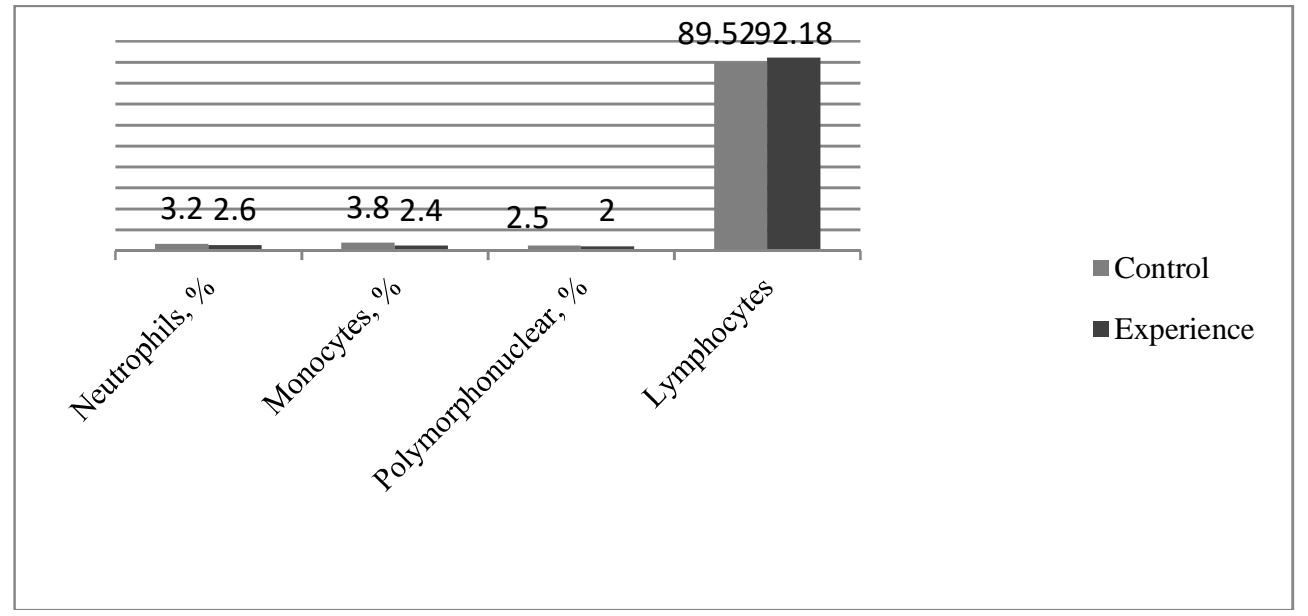

Fig. 7. Leukocyte formula of female African catfish catfish (\%)

In second place in terms of specific gravity in white blood is the fraction of neutrophils. The relative number of neutrophils in the blood of fish of both groups at the beginning and at the end of the experiment was within the physiological norm. However, this indicator in the blood of the experimental group had a significant decrease, compared with the control group. So, the number of neutrophils in specimen of the control group was in the range of $3.0-3.2 \%$, in the experimental group $-2.5-2.6 \%$.

Catfish blood is represented by polymorphonuclear cells. These are round cells that have a horseshoe-shaped segmented nucleus and a granular cytoplasm. Eosinophils involved in the development of the body's immune response during helminthiases and protozoa are also classified as these cells. The number of polymorphonuclear cells is within: in the experimental group $-0.9-2.0 \%$, in the control group $-0.8-2.5 \%$, depending on sex.

The analysis of the leukocyte profile of the catfish organism indicates that, against the background of the use of the probiotic Subtilis, a significant increase in the absolute number of lymphocytes is observed in fish, while the relative number of neutrophils, monocytes, and polymorphonuclear cells decreases. A decrease in the relative number of neutrophils, monocytes, and polymorphonuclear cells can be explained by an increase in the proportion of lymphocytes.

As a result, we detected leukocytosis in the blood of catfish within the physiological norm, with a distinct lymphocytosis. Also a slight decrease in the proportion of neutrophils, while maintaining their high numbers was revealed. All this indicates a high degree of development of the cellular link of the catfish immune system.

Our results fit well the previously obtained data on the influence of the probiotic Sporothermin on the leukogram of African catfish [14].

\section{Conclusion}

Differences in the content of red blood cells were detected in the control and in the experimental group of catfish treated with the probiotic Subtilis. The number of red blood cells in catfish treated with the probiotic increased significantly.

Against the background of the use of the "Subtilis" probiotic, the number of blastocytes in the bloodstream decreases, which indicates a positive effect of the probiotic microorganisms on blood formation.

Our results showed that the use of the probiotic Subtilis had a positive effect on the erythron system and the leukogram of African catfish as a whole.

It is well known that an increase in the number of red blood cells leads to an improvement in the supply of tissues and organs with oxygen and positively affects metabolic processes in the body of fish.

The use of the probiotic Subtilis in the diet of African catfish optimizes the physiological and bio-chemical status of fish blood, strengthens the immune system, maintaining fish health and increasing fish production performance. In general, the use of probiotics is a factor ensuring the safety of fish products for the final consumer - the human being.

\section{References}

1. B.C. De, D.K. Meena, B.K. Behera, P. Das, A.P. Sharma, P.K. Das Mohapatra, Fish Physiology and Biochemistry, 40(3), 921-971 (2014)

2. C.R. Serra, I. Guerreiro, R. Santos, A. Oliva-Teles, P. Enes, E.M. Almeida, F. Tavares, D.L. Merrifield, Scientific Reports, 9(1), 6384 (2019) 
3. M. Soltani, A.J. Lymbery, K. Ghosh, S.H. Hoseinifar, V. Kumar, S. Roy, E. Ring $\varnothing$, Reviews in Fisheries Science and Aquaculture, 27(3), 331-379 (2019)

4. G.C. Román, R. Gadhia, R.E. Jackson, A.N. Román, J. Reis, Revue Neurologique (2019)

5. C.-C. Yi, Y.-T. Chang, S.-Y. Hu, C.-H. Liu, K.-P. Chuang, Fish \& Shellfish Immunology, 93, 124-134 (2019)

6. A. Mukherjee, K. Ghosh, G. Chandra, Aquaculture, 512, 734302 (2019)

7. B. Kazuń, K. Kazuń, Fisheries \& Aquatic Life, 27(3), 130-135 (2019)

8. M.J. Zorriehzahra, M. Adel, S.T. Delshad, R. Tiwari, K. Karthik, K. Dhama, C.C. Lazado, Veterinary Quarterly, 36(4), 228-241 (2016)

9. M. Asaduzzaman, A. Shakil, N.F. Haque, M.N.A. Khan, E. Sofia, D. Ikeda, S. Kinoshita, A.B. Abol-
Munafi, Aquaculture Reports, 9, 37-45 (2018)

10. M. Fujimoto, B. Lovett, R. Angoshtari, P. Nirenberg, T.L. Marsh, T.P. Loch, K.T. Scribner, Microbial. Ecology, 75(1), 22-37 (2018)

11. M.A.O. Dawood, S. Koshio, M. Ishikawa, S. Yokoyama, W.-L. Wang, Z. Yukun, A. Olivier, M. El-Sabagh, Fish Physiology and Biochemistry, 43(1), 179-192 (2017)

12. S. Zhou, A. Zhang, H. Yin, W. Chu, Frontiers in cellular and infection microbiology, 6, 184 (2016)

13. H. Ghomrassi, O.B. Braiek, K. Hani, T. Ghrairi, Y. Choiset, T. Haertlé, J.-M. Chobert, Diseases of Aquatic Organisms, 118(1), 31-43 (2016)

14. T. Shlenkina, E. Romanova, V. Romanov, V. Lyubomirova, L. Shadyeva, E. Spirina, M. Mukhitova, IOP Conference Series: Earth and Environmental Science, 403, 012219 (2019) 